\title{
Study of Multistoried Buildings with Oblique Columns
}

\author{
Rohan Singh, Vikas Prabhakar \\ Civil Engineering Department, \\ Gautam Buddha University, Greater Noida (U.P.), India.
}

\begin{abstract}
The Oblique Columns are not conventionally parallel or at right angles to a specified line means they're inclined or slanted or Rotated at an angle. Oblique columns are stiffer as $\mathrm{RC}$ frames and so the initial stiffness of the RC frames largely depends upon the stiffness of oblique column. For oblique column of below $90^{\circ}$, there'll be a decrease in plan dimensions and for above $90^{\circ}$, there'll be increase in plan dimensions as we reach upper floors. It affects the lateral stiffness of the buildings. Compared to standard columns, oblique columns of below $90^{\circ}$ have lesser storey shear values. Oblique columns of above $90^{\circ}$ have higher storey shear values. Stiffness of RC frames significantly depends on the distribution of oblique column within the frame. The lateral loads are resisted by structure with Oblique columns, the highest storey displacement is incredibly much less in Oblique structure as compared to the easy RC Frame building. Analyzing the behavior of oblique columns is that the main purpose of this study. Analysis has been meted out by considering columns of 80, 82, 84, 86, 88 and 90 degrees. Static and Dynamics analysis should be finished these Columns. Ground motion performance of oblique columns are analyzed by Response spectrum method. The analysis of the buildings will be done by using ETAB software and the performance will be analyzed by same building with oblique columns replaced with normal vertical columns. Analysis has been meted out by considering columns of 80, 82, 84, 86, 88 and 90 degrees.
\end{abstract}

Index Terms- Autocad, Etabs, Oblique columns, Lateral load resisting structure, Story drift, Story displacement.

\section{INTRODUCTION}

The fast increment of the urban populace in creating nations, for example, India, has constrained the revaluation of the significance of tall structures with various size and shape which prompts distinctive perspective proportion of the structures. The basic frameworks of tall structures are normally not very efficient with the impacts of wind\& tremor, the breeze seismic tremor structure connections and afterward decides the wind loads \& earthquake forces as proportional static loads. It has been demonstrated that the angle proportion of building influences the impact of wind and seismic tremor powers on building. These postulation study the various instances of viewpoint proportion of the structure and impact of wind and Earthquakes are occasional forces on structures that may occur rarely during the lifetime of buildings. It is also likely that a structure may not be subjected to severe earthquake forces during its design lifetime. Reinforced Concrete Multi-Storied buildings (RCMS) are supposed to be of engineered construction in the sense that they might have been analyzed and designed to meet the provisions of the relevant codes of practice and building bye-laws; the construction might have been supervised by trained persons. In such cases, even if earthquake forces have not been considered precisely, the structures would have adequate in-built strength and ductility to withstand some level of earthquake intensity.

In India, in recent decades, the use of civil engineering is becoming more and more popular and the technological situation has improved considerably. The wind engineering needs a way to get more information solutions to various critical wind problems. Including various fields such as (i) Fluid energy (ii) potential once calculations and (iii) structural properties. The spirit, generally, has two main effects on long structures: First, they are strong too Design times and installations, second distributes wind into and around a building, it is called wind pressure. The wind pressures in the building are influenced building geometry, angle of wind events, surrounding and signs of wind flow. There are many situations where database, codes / standards and analysis are available. Methods cannot be used to measure wind pressure coefficients and wind loads on the claddings and supports system of structures, for example, aerodynamic formation of the structure is unusual.

Various worldwide structure and examination programming, for example, ETABS, SAP2000, MIDAS/Gen and SATWE are continually developing themselves, yet stayed individual impediments. In this paper, reaction range, time history and connecting piece inplan stresses examination was executed joined with a reasonable task, by the projects referenced above, which were additionally looked at following the investigation results.

\section{NEED FOR PRESENT STUDY}

- From various design investigations, it is observed that oblique columns of buildings significantly affect the earthquake forces on the buildings.

- This study shows that certain inclination of oblique columns of buildings prone to wind and EQ Force phenomena which can generate high dynamic loads and govern the design.

- This study will ignite an interest on the use of oblique column in lateral load resistant design of high rise structures.

- It would be useful in showing the importance of inclination of oblique columns on lateral load resisting capacity of high rise Structures.

\section{LITERATURE REVIEW}

Girish kumar G.M and S M Maheswarappa: Studied by considering the different angles of oblique columns and also 
different storey of the building. The plan of $36 \mathrm{~m} \times 36 \mathrm{~m}$ is considered with four different types of angles of that is 80 , $84,88,90,94,100$ by considering 8 -storey building, comparing to multi-storeyed buildings with normal columns, the multi-storeyed buildings with oblique columns Oblique columns show $38 \%$ lesser story drift than normal columns. Oblique columns of 92, 96 and 100 degrees have $30 \%$ lesser top story displacement than conventional column. Multistoried building with oblique column of greater than 90 degree have story shear and story stiffness greater than conventional columns. Hence, the oblique columns is more seismic resistant than conventional columns.

Kona Narayana Reddy, Dr.E.Arunakanthi: presented a study on analysis of concrete diagrid structure and compared with conventional concrete building. Their study shows lateral loads are resisted by structure with Oblique columns, the top storey displacement is very much less in Oblique structure as compared to the simple RC Frame building. Structure provides more resistance in the oblique column building which makes the structural system more effective. The overall results suggested that Oblique column is excellent seismic control for high-rise symmetric Buildings.

Kai Hu, Yimeng Yang, Suifeng Mu, Ge Qu: All the results of response spectrum analysis calculated by different programs are basically similar for structures with oblique columns, while ETABS may miss the statistic of oblique columns, which need to be paid attention to in future designs. The results of time history analysis by SAP2000 and ETABS are roughly similar. However, SAP2000 does not have the concept of storey which made the postprocessing much more complicated for analyzing oblique columns. Therefore, to the regular structure, ETABS is recommended and to those gymnasium or space truss structures, SAP2000 has its irreplaceable advantages.

T. K. Datta (2010) in "Seismic Analysis of Structures" have presented an overview of various dynamic analysis procedures for use in seismic design of structures. A discussion of the determination of the structural response to be used in association with the equivalent static force method and Response spectrum method is presented. Prashant Dhadve, Alok Rao in Assessment of "P-Delta Effect on High Rise Buildings". Increasing stiffness of building by providing suitable cross section or by increasing stiffness building by providing confinement to the structure can bring response of structure within acceptable limit.

\section{METHODOLOLGY}

1- Extensive literature survey by referring books, technical papers or research papers carried out to understand basic concept of topic.

2- Identification of need of research.

3- Formulation of stages in analytical work which is to be carried out.

4- Data collection.

5- 13 storey building is considered for the analysis.
6- The model has prepared on ETABS and planned on AUTOCAD for the several angle of inclinations of buildings with oblique column.

7- Wind loads and Earthquake load for the building according to IS has done by using the various parameters.

8- Application of calculated wind loads and Earthquake load on the modeled buildings is to be done.

9- Comparative studies done for axial loads on column, storey shear, lateral story displacement, story drift, wind intensity for the various aspect ratio of buildings and determination of structurally efficient of building is to be done. Interpretation of results and conclusion.

\section{SPECIFIC STEPS IN SUTUDY}

- To compare the results of the analysis on the Maximum story displacement, Story shear, Story stiffness and story drift of a multistorey structural building with normal and oblique columns.

- To investigate the seismic performance of a multistorey structural building with normal and oblique column by Response Spectrum analysis.

- To study the behavior of tall structures with oblique columns when subjected to wind loads and Earthquake force.

- To study the effect of inclination of oblique column of the building in plan on the behavior of the structure.

- To study same floor area of the building with different angle of inclination on oblique column.

- To determine the effect of wind load and Earthquake force on various parameters like storey drifts, lateral displacements in the building.

- To define the most efficient angle of inclination in high rise buildings which can provide most effective wind load and Earthquake force resistant capacity by observing the comparative studies.

- To model high rise structure in ETAB Software.

\section{APPROACH}

1- Adoption of several models of RC high-rise structure buildings consisting of 13 storey and for the three types of structural systems in resisting lateral forces. The designing models adopt walls of the central core of the stairs and lifts as essential shear walls to resist shear forces in addition to surrounding shear walls in both directions. The thickness for slab and cross-sections dimensions of reinforced concrete elements are identified and after the process of analysis and design using technical Analysis-Design Cycle for imposed designing models and make sure to achieve the Indian code conditions in structures design to resist earthquakes about dimensions and ratio of reinforcement for each structural element, then after that, study the conclusion models again after modification to the dimensions of cross-sections of some or all structural elements (beams - columns - 
slabs, oblique columns), then the processes of analysis, design is made and new models are concluded and so on until reaching to the final models that all its structural elements achieve design code conditions as well as to achieve lower cost.

2- Adoption of structural analysis program ETABS.v18 in analysis and structural design models of RC high-rise structure buildings and extraction the results of the design for the types of structural systems with oblique column and calculation amounts of concrete and steel for whole structure building and all models using Excel program and making a comparison between the models.

3- Drawing relations between the inclination of oblique column of different models and the storey displacements.

4- Determination the best and the appropriate of structural systems and the degree of inclination for the oblique columns for the different $\mathrm{RC}$ high-rise buildings in the number of stories and determination the percentage of saving achieved by oblique columns.

\section{PLANNING ON AUTOCAD}

AutoCAD could be a computer-aided tool that permits many various forms of designers to make diverse varieties of drawings and styles. This program helps designers create their designs way more quickly than by hand and offers many quick, easy, and useful features, like copy and paste. AutoCAD has numerous capabilities that may be applied to an array of projects in various fields. Various varieties of designers are possibly to use the program and it's more common in design-centered fields, like architecture and engineering. However, many other professions, like fine artists and mathematicians, may use the program to make visuals for his or her work.

Salient Features: The design data shall be as follows.

1- Utility of Buildings: Multipurpose.

2- No of Storey: G+12

3- Shape of the Buildings: Rectangular.

4- No. Of Staircases: Two

5- No. Of Lifts: One

6- Types of Walls: None

7- Geometric Details

- Ground floor height : $3.6 \mathrm{M}$

- Floor-To-Floor Height: $3.6 \mathrm{M}$

- Height of Plinth: 0.6 M above G.L

- Depth of Foundation: 3 M below G.L

8- Material Details:
- Concrete Grade: M40 (COLUMNS AND BEAMS)

- HYSD REINFORCEMENT of Grade Fe500
- Bearing Capacity of Soil(assumed): 200 kN/M ${ }^{2}$

9- Type Of Construction: Ordinary moment resisting R.C.FRAME structure.

10- Inclination of Periphery columns (Oblique columns) varies from 90 degree to 80 degree in different models.

11- Total height of building in all models is taken same as $47.58 \mathrm{~m}$.

12- Inclination of oblique column varies from 90 degree to 80 degree so plan dimensions goes on decreasing from bottom to top.

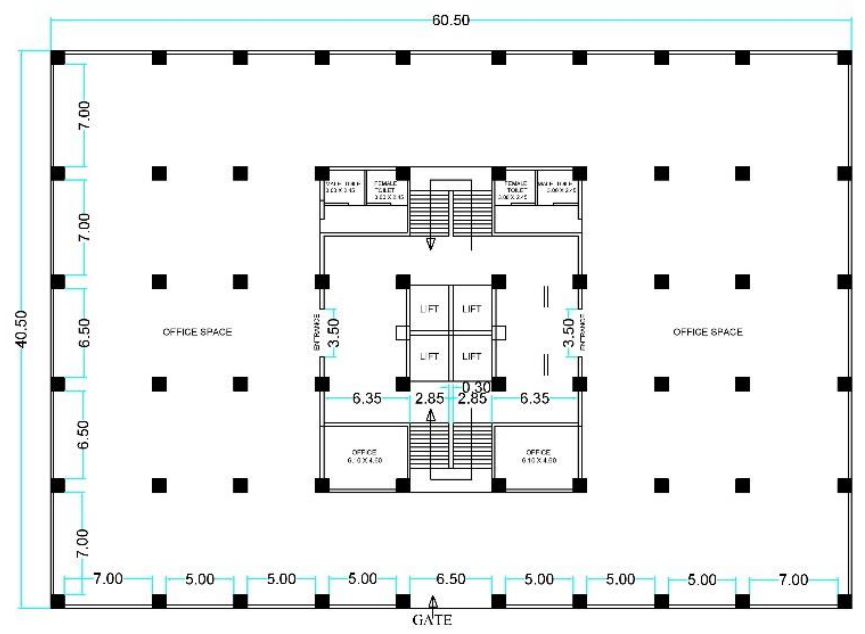

Figure - 1: GROUND FLOOR PLAN

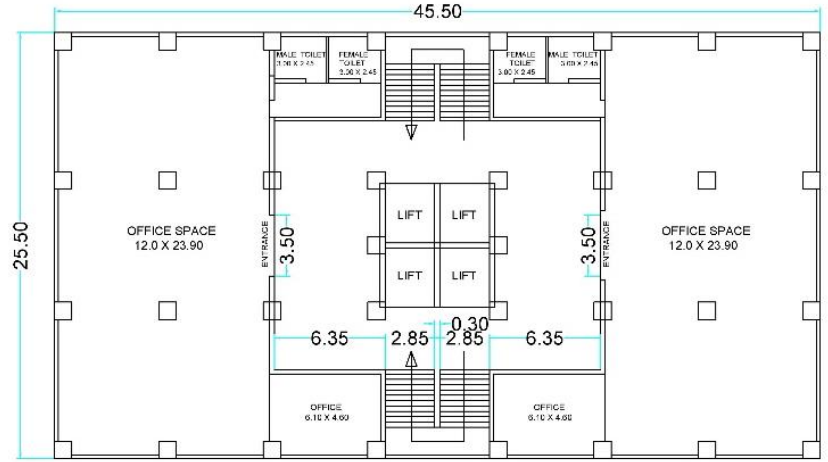

Figure - 2: REDUCED 13TH FLOOR PLAN

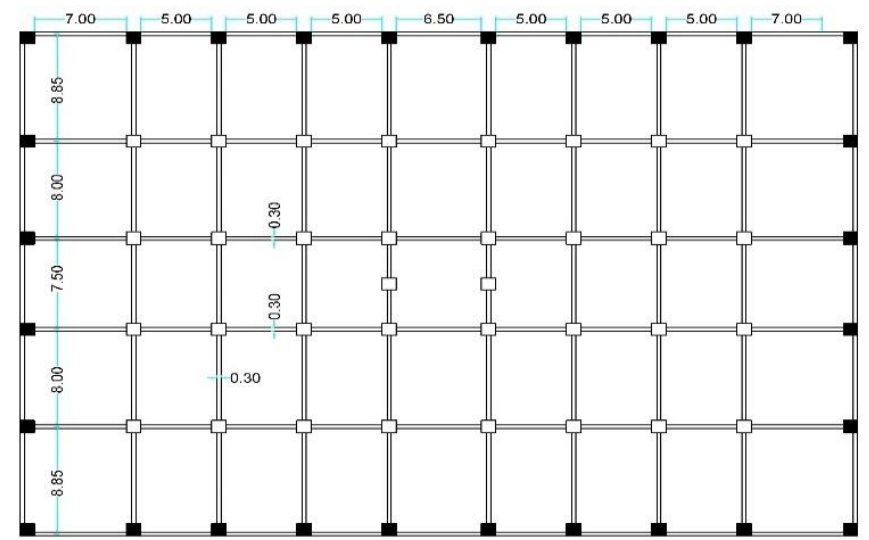

Figure - 3: BEAMS AND COLUMN LAYOUT 


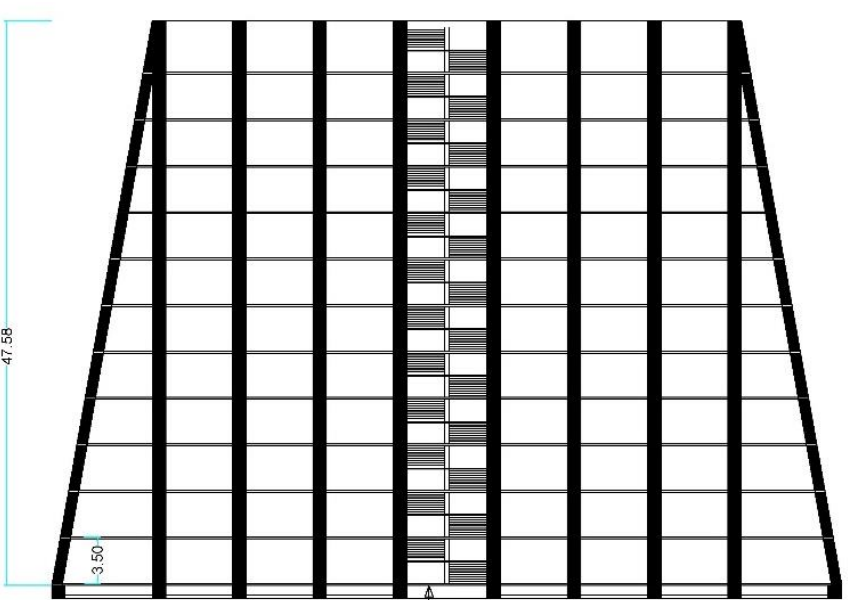

Figure - 4: FRONT ELEVATION OF BUILDING WITH 80 DEGREE OBLIQUE COLUMN

Table -1: Beam sizes considered

\begin{tabular}{|c|c|c|}
\hline Structure & Beam $350 \times 600$ & Beam 300 x 600 \\
\hline Beam slab structure & All beams & Lift core \\
\hline
\end{tabular}

Table -2: Internal Column sizes considered

\begin{tabular}{|c|c|}
\hline Size & Position \\
\hline $1000 \times 1000$ & Columns of lift core \\
\hline $800 \times 800$ & Other than lift cores \\
\hline
\end{tabular}

Table -3: Peripheral Column sizes considered (Oblique Column)

\begin{tabular}{|c|c|}
\hline Size & Storey Level \\
\hline $1000 \times 1000$ & Base to $13^{\text {th }}$ floor \\
\hline
\end{tabular}

Table -4: Details of buildings:

\begin{tabular}{|c|c|}
\hline Slab Thickness & Not considered \\
\hline Thickness of shear wall & $25 \mathrm{KN} / \mathrm{m} 3$ \\
\hline Density of concrete & M 40 \\
\hline Grade of concrete & Columns, Beams and slabs - \\
\hline Grade of Steel & $\mathrm{HN} 500$ \\
\hline Live load (including floor & Typical $-5 \mathrm{kN} / \mathrm{m}^{2}$ Roof level -3 \\
finishes) & $\mathrm{kN} / \mathrm{m}^{2}$ \\
\hline Super imposed load (SDL) & Typical - $4 \mathrm{kN} / \mathrm{m}^{2}$, Rol -2 \\
\hline (including furnishings) & \\
\hline Live load contribution & \\
\hline
\end{tabular}

Table -5: Frame structure data:

\begin{tabular}{|c|c|}
\hline Length of building & $60.50 \mathrm{~m}$ \\
\hline Width of building & $40.50 \mathrm{~m}$ \\
\hline Height of building & $47.58 \mathrm{~m}$ \\
\hline Typical storey height & $3.6 \mathrm{M}$ \\
\hline Wall load & $\begin{array}{c}\text { Not considered (open frame } \\
\text { structure) }\end{array}$ \\
\hline Grade of concrete & M40 \\
\hline Grade of steel & HYSD500 \\
\hline Thickness of slab & $200 \mathrm{~mm}$ \\
\hline
\end{tabular}

\section{ETABS BASIC INPUT DATA}

Table -6: BASIC GRID INPUT (CUSTOM GRID SPACING IN X AND Y DIRECTIONS).

\begin{tabular}{|l|l|l|l|l|l|l|l|l|l|}
\hline $\mathrm{x}$ & $\begin{array}{l}6 \\
\mathrm{~m}\end{array}$ & $\begin{array}{l}6 \\
\mathrm{~m}\end{array}$ & $6 \mathrm{~m}$ & $\begin{array}{l}6 \\
\mathrm{~m}\end{array}$ & $\begin{array}{l}7.5 \\
\mathrm{~m}\end{array}$ & $\begin{array}{l}6 \\
\mathrm{~m}\end{array}$ & $\begin{array}{l}6 \\
\mathrm{~m}\end{array}$ & $\begin{array}{l}6 \\
\mathrm{~m}\end{array}$ & $\begin{array}{l}8 \\
\mathrm{~m}\end{array}$ \\
\hline $\mathrm{y}$ & 8 & 8 & 7.5 & 8 & $8 \mathrm{~m}$ & - & - & - & - \\
& $\mathrm{m}$ & $\mathrm{m}$ & $\mathrm{m}$ & $\mathrm{m}$ & & & & & \\
\hline
\end{tabular}

Table -7: DEFINE NUMBER OF STOREYS AND CUSTOM STOREY HEIGHTS.

\begin{tabular}{|l|l|}
\hline STORY & HEIGHT \\
\hline 13 & 3.6 \\
\hline 12 & 3.6 \\
\hline 11 & 3.6 \\
\hline 10 & 3.6 \\
\hline 9 & 3.6 \\
\hline 8 & 3.6 \\
\hline 7 & 3.6 \\
\hline 6 & 3.6 \\
\hline 5 & 3.6 \\
\hline 4 & 3.6 \\
\hline 3 & 3.6 \\
\hline 2 & 3.6 \\
\hline 1 & 3.6 \\
\hline Base & 3.6 \\
\hline
\end{tabular}

Table -8: DEFINE SECTION PROPERTIES (BEAMS, COLUMNS, SLABS)

\begin{tabular}{|c|c|}
\hline COMPONENT & SIZE \\
\hline Beams & $350 \mathrm{~mm} \mathrm{X} \mathrm{600mm}$ \\
\hline Internal Columns & $800 \mathrm{~mm} \mathrm{X} \mathrm{800mm}$ \\
\hline Oblique Columns at periphery & $1000 \mathrm{~mm} \mathrm{X} \mathrm{1000mm}$ \\
\hline Slab & $200 \mathrm{~mm}$ \\
\hline Lift Core column & $1000 \mathrm{~mm} \mathrm{X} \mathrm{1000mm}$ \\
\hline Lift Core Beam & $300 \mathrm{~mm} \mathrm{X} \mathrm{600mm}$ \\
\hline
\end{tabular}

Table -9: DEFINE MATERIAL PROPERTIES.

\begin{tabular}{|c|c|}
\hline M40 Concrete & Properties \\
\hline Directional Symmetry type & Isotropic \\
\hline Weight per unit volume & $24.9926 \mathrm{kN} / \mathrm{m}^{3}$ \\
\hline Mass per unit volume & $2548.538 \mathrm{~kg} / \mathrm{m}^{3}$ \\
\hline Modulus of elasticity, E & $31622.78 \mathrm{MPa}$ \\
\hline Poisson's Ratio & 0.2 \\
\hline Coefficient of thermal expansion, A & $0.00000551 / \mathrm{C}$ \\
\hline Shear modulus, G & $13176.16 \mathrm{MPa}$ \\
\hline Hek & $40 \mathrm{MPa}$ \\
\hline Material type & \\
\hline Deboriar & Uniaxial \\
\hline Weight per unit volume & $76.9729 \mathrm{kN} / \mathrm{m}^{3}$ \\
\hline Mass per unit volume & $7849.047 \mathrm{~kg} / \mathrm{m}^{3}$ \\
\hline Modulus of elasticity, E & $200000 \mathrm{MPa}$ \\
\hline Coefficient of thermal expansion, A & $0.00001171 / \mathrm{C}$ \\
\hline Minimum yield strength, Fy & $500 \mathrm{MPa}$ \\
\hline Minimum tensile strength, Fu & $545 \mathrm{MPa}$ \\
\hline Expected yield strength, Fye & $550 \mathrm{MPa}$ \\
\hline Expected tensile strength, Fue & $599.5 \mathrm{MPa}$ \\
\hline
\end{tabular}

Table -10: DEFINE LOAD PATTERN

\begin{tabular}{|l|c|c|}
\hline \multicolumn{1}{|c|}{ LOAD } & VALUE & $\begin{array}{c}\text { IS CODE } \\
\text { REFERED }\end{array}$ \\
\hline Dead & Program calculated & IS $456: 2000$ \\
\hline Live & $5 \mathrm{kN} / \mathrm{m}^{2}$ (including floor finish) & IS $875: 1987$ \\
\hline & $\begin{array}{c}\text { Live at top story } \\
\text { 3kN/m² (including floor finish) }\end{array}$ & IS $875: 1987$ \\
\hline Wind $+\mathrm{X}$ & Basic wind speed, $\mathrm{V}_{\mathrm{b}}$ & $47 \mathrm{~km} / \mathrm{s}$ \\
\hline & Windward coefficient, $\mathrm{Cp}=0.8$ & IS875:1987 \\
\hline & Leeward Coefficient, $\mathrm{Cp}=0.5$ & IS875:1987 \\
\hline & Terrain category $=2$ & IS875:1987 \\
\hline & Structure class $=\mathrm{B}$ & IS875:1987 \\
\hline & Risk coefficient factor & IS875:1987 \\
$\mathrm{k} 1=1$ & $\mathrm{k} 2=1$ \\
\hline $\mathrm{EQ}+\mathrm{X}$ & Seismic zone factor, $\mathrm{Z}=0.36$ & IS $1893: 2002$ \\
\hline
\end{tabular}




\begin{tabular}{|c|c|c|}
\hline & Site type II & IS 1893:2002 \\
\hline & Importance factor, I=1 & IS 1893:2002 \\
\hline & $\begin{array}{c}\text { Time period, T (program } \\
\text { calculated) }\end{array}$ & IS 1893:2002 \\
\hline EQ+Y & $\begin{array}{c}\text { Response reduction factor, } \\
\mathrm{R}=5\end{array}$ & IS 1893:2002 \\
\hline & Seismic zone factor, Z= 0.36 & IS 1893:2002 \\
\hline & Site type II & IS 1893:2002 \\
\hline & Importance factor, I=1 & IS 1893:2002 \\
\hline & $\begin{array}{c}\text { Time period, T (program } \\
\text { calculated) }\end{array}$ & IS 1893:2002 \\
\hline & $\begin{array}{c}\text { Response reduction factor, } \\
\mathrm{R}=5\end{array}$ & IS 1893:2002 \\
\hline
\end{tabular}

Table -11: DEFINE LOAD CASE

\begin{tabular}{|l|l|}
\hline Load case name & Load case type \\
\hline Dead & Linear Static \\
\hline Live & Linear Static \\
\hline EQ+X & Linear Static \\
\hline EQ+Y & Linear Static \\
\hline WIND & Linear Static \\
\hline RSP-XY & Response Spectrum \\
\hline
\end{tabular}

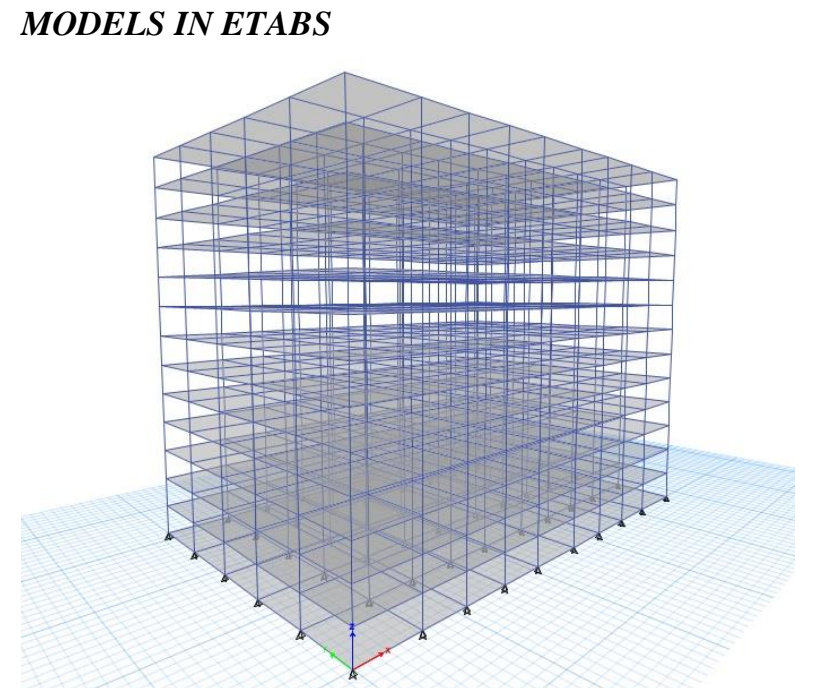

Figure - 5: MODEL 1- Multistoried building with vertical column of $90^{\circ}$

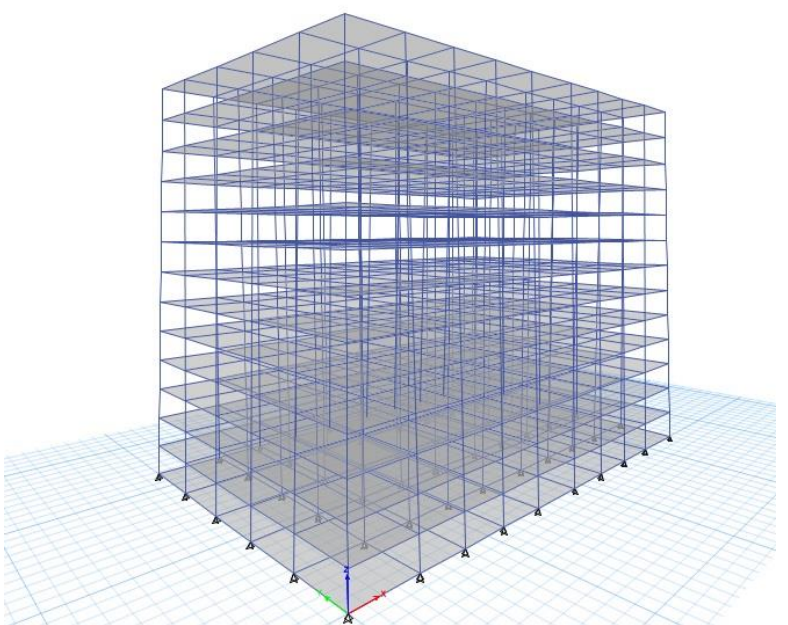

Figure - 6: MODEL 2- Multistoried building with oblique column of $88^{\circ}$

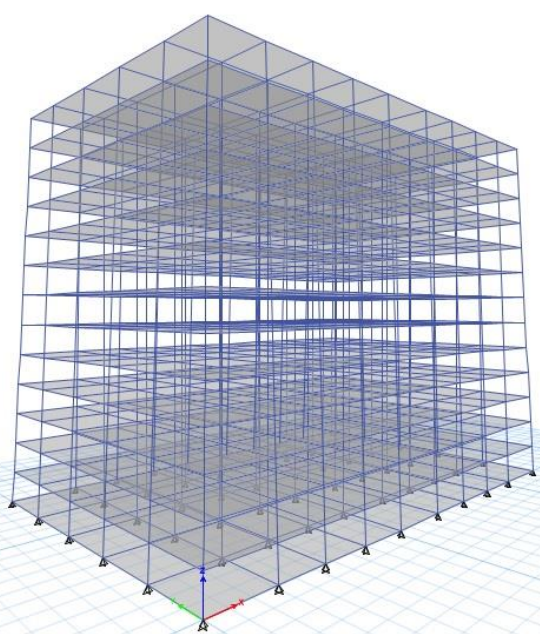

Figure - 7: MODEL 3- Multistoried building with oblique column of $86^{\circ}$ 


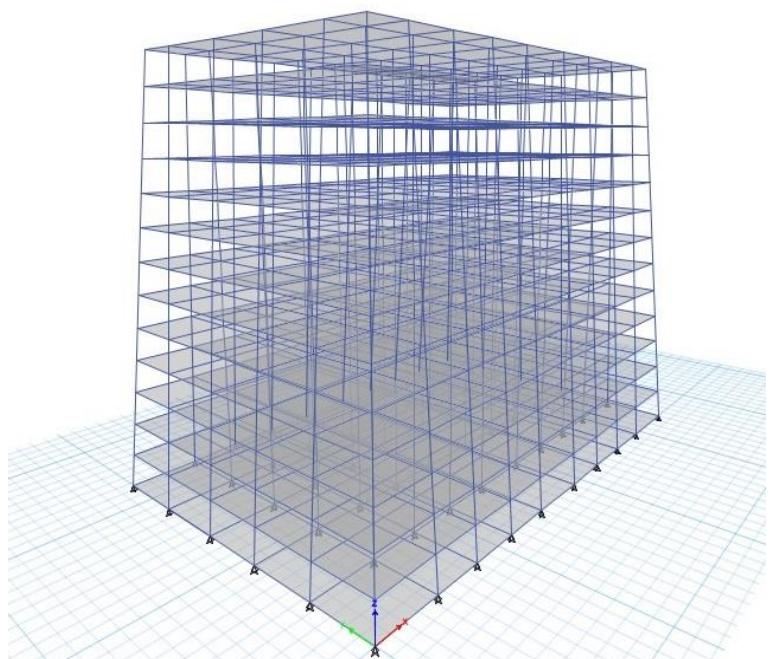

Figure - 8: MODEL 4- Multistoried building with oblique column of $84^{0}$

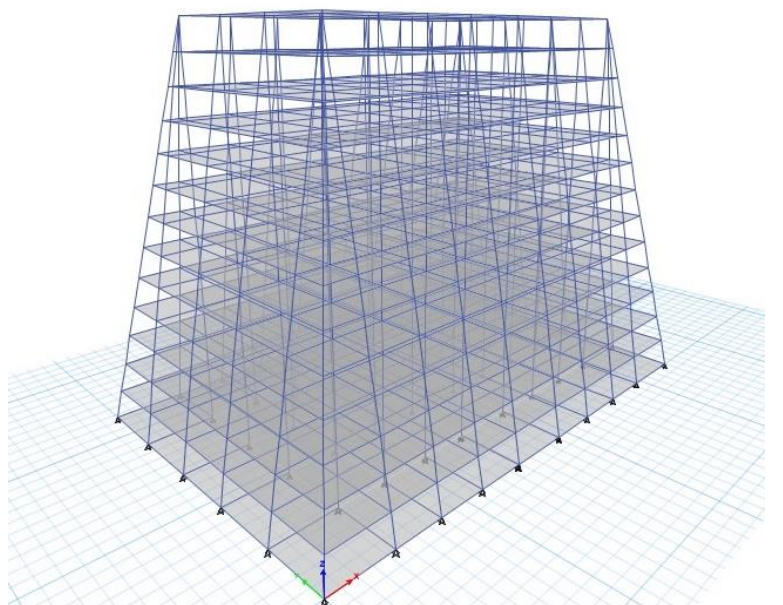

Figure - 9: MODEL 5- Multistoried building with oblique column of $82^{0}$

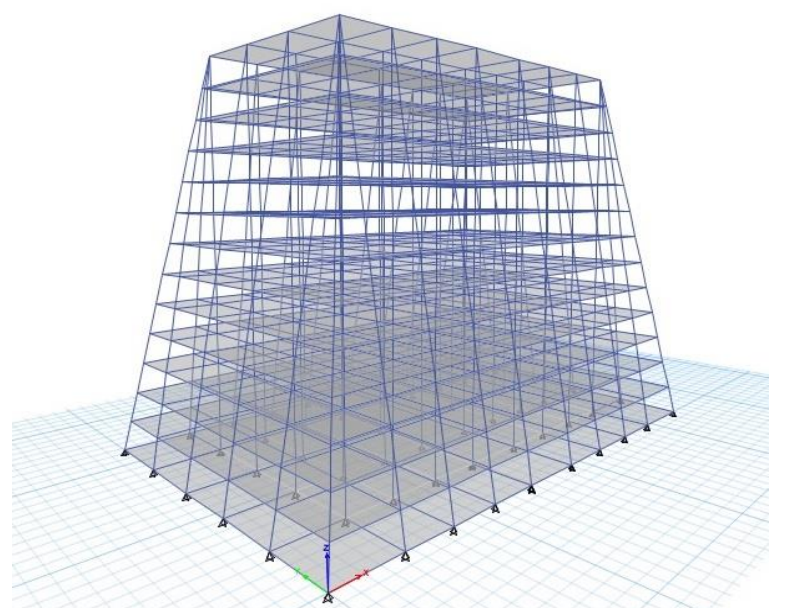

Figure - 10: MODEL 6- Multistoried building with oblique column of $80^{\circ}$

\section{ANALYSIS}

\section{RESPONSE SPECTRUM ANALYSIS}

Response spectrum method stands from modal method or mode superposition method. It's best suited for the kind of structure where modes fundamental single importantly influencing the response of the building. Basically this method is use for the dynamic analysis of building. It's broadly areas of discontinuity or irregularity i.e. as symmetrical. It's available for the analysis of forces and deformations within the multi-story buildings reason behind avg. intensity ground shaking which is said to the moderately huge but in linearly response within the buildings. In its form, this method for linear response is suitable to arbitrary 3-D structures. A whole modal analysis defines the history of responses. The whole history of responses is must needed for designing. The strategy accustomed attach the ends up in the Response spectrum method which is more critical to get the accurate values. Within the analysis, when every effective mode used then the acceptable technique most probable for combining the result. Within which the strategy Square-root-of-sum-of square method mostly used because within which the simply squares sum of all own results and at that time takes the root of the result. And also most accurate technique is CQC (complete quadratic combination). Within which the spectral results using for damping and weight ratio of relative frequencies. The concept may be a dynamic analysis into partly static and partly dynamic for locating the most displacement. Is restricted only to one mode of vibration of structure.

Response spectroscopic analysis could be a method to estimate the structural response to short, nondeterministic, transient dynamic events. Samples of such events are earthquakes and shocks. Since the precise time history of the load isn't known, it's difficult to perform a time-dependent analysis. Because of the short length of the event, it cannot be considered as an ergodic ("stationary") process, so a random response approach isn't applicable either. A response spectrum could be a function of frequency or period, showing the height response of a straightforward harmonic oscillator that's subjected to a transient event. The response spectrum could be a function of the natural frequency of the oscillator and of its damping. Thus, it's not an instantaneous representation of the frequency content of the excitation (as during a Fourier transform), but rather of the effect that the signal has on a postulated system with one degree of freedom (SDOF).

In order to perform the seismic analysis and style of a structure to be built at a specific location, the particular time history record is required. However, it's insufferable to own such records at each and each location. Further, the seismic analysis of structures can not be administered simply supported the height value of the bottom acceleration because the response of the structure rely upon the frequency content of ground motion and its own dynamic properties. To beat the above difficulties, earthquake response spectrum is that the most well liked tool within the seismic analysis of structures. There are computational advantages in using the response spectrum method of seismic analysis for prediction of displacements and member forces in structural systems. The strategy involves the calculation of only the utmost values of the displacements and member forces in each mode of vibration using smooth design spectra that are the typical of several earthquake motions. 
This study deals with response spectrum method and its application to various types of the structures. The codal provisions as per IS: 1893 (Part 1)-2002 code for response spectrum analysis of multi-story building is also summarized.

\section{RESPONSE SPECTRA}

Response spectra are curves plotted between maximum response of SDOF system subjected to specified earthquake ground motion and its time period (or frequency). Response spectrum are often interpreted because the locus of maximum response of a SDOF system for given damping ratio. Response spectra thus helps in obtaining the peak structural responses under linear range, which might be used for obtaining lateral forces developed in structure thanks to earthquake thus facilitates in earthquake-resistant design of structures.

Usually response of a SDOF system is set by time domain or

frequency domain analysis, and for a given time period of system, maximum response is picked. This process is sustained for all range of possible time periods of SDOF system. Final plot with system time period on $\mathrm{x}$-axis and response quantity on $y$-axis is that the required response spectra per specified damping ratio and input ground motion. Same process is administered with different damping ratios to get overall response spectra.

\section{ANALYSIS OUTPUT DATA}

After completing analysis of different models with different angle of inclinations, these results have been generated and tabulated in systematic manner. Linear static analysis is performed for all models for seven storey buildings as listed. Loads are calculated and distributed as per code IS 1893(Part-I):2002 using ETABS. The results obtained from analysis are compared with respect to the following parameters. The parameters which were studied are Story drifts, Storey displacements, Axial forces, Response spectrum drifts, Time period for all models in zone IV. Modelling of 13- storeys R.C.C. framed building is done on the ETABS software for analysis. Post analysis of the structure, maximum shear forces, bending moments, and maximum storey displacement are computed and then compared for all the analyzed cases.

All models are listed below:

1- Building with vertical columns of 90 degree. 2- Building with oblique columns of 88 degree.

3- Building with oblique columns of 86 degree.

4- Building with oblique columns of 84 degree.

5- Building with oblique columns of 82 degree.

6- Building with oblique columns of 80 degree.

\section{MAXIMUM STOREY DISPLACEMENTS}

Building with vertical columns of 90 degree

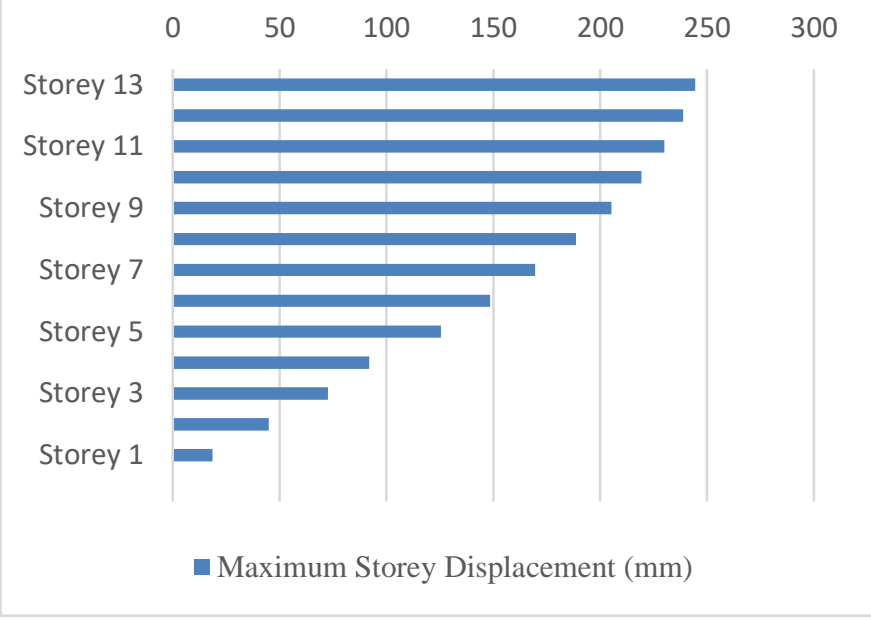

Building with oblique columns of 88 degree

0

50

100

150

200

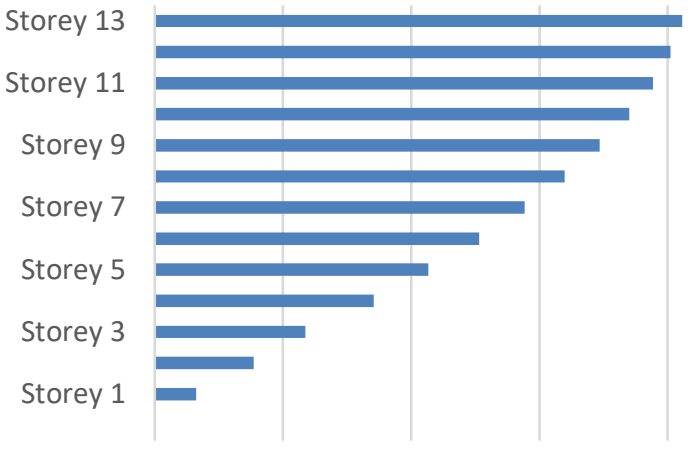

- Maximum Storey Displacement (mm)

Building with oblique columns of 86 degree

0

50

100

150 200

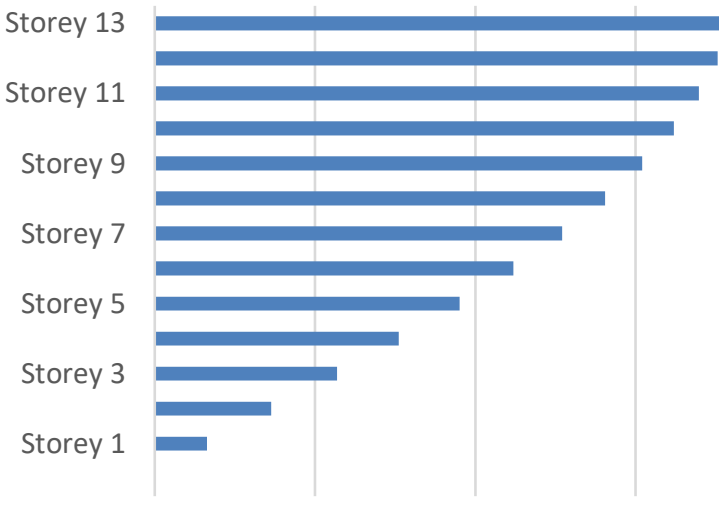

- Maximum Storey Displacement (mm) 
Building with oblique columns of 84 degree

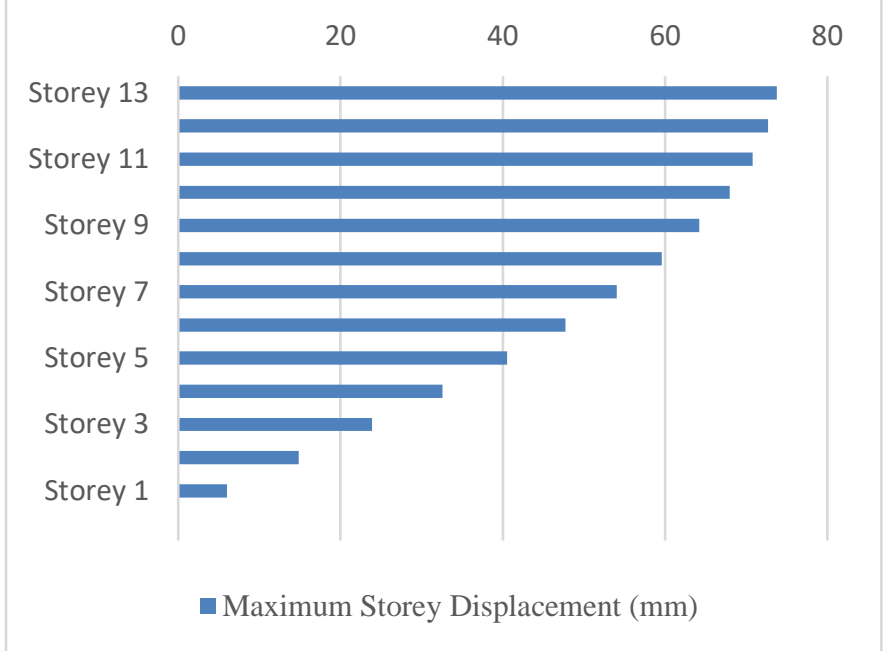

Building with oblique columns of 82 degree

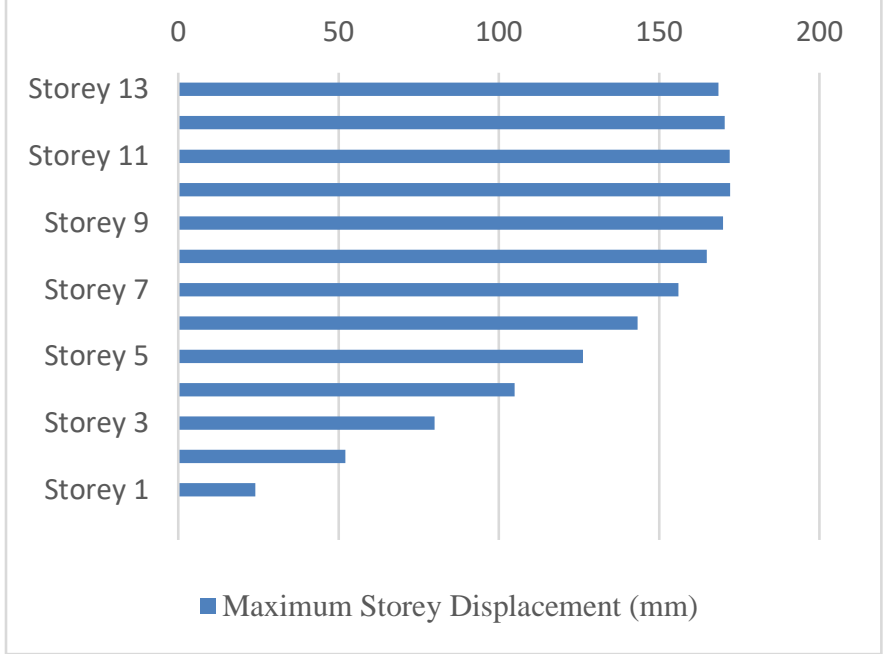

Building with oblique columns of 80 degree

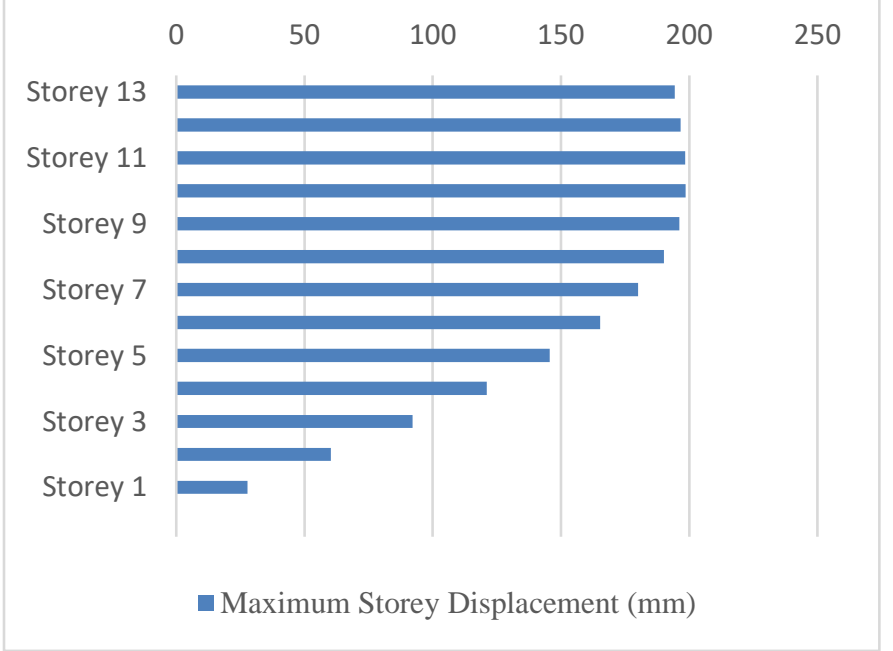

Maximum storey displacement $(\mathrm{mm})$

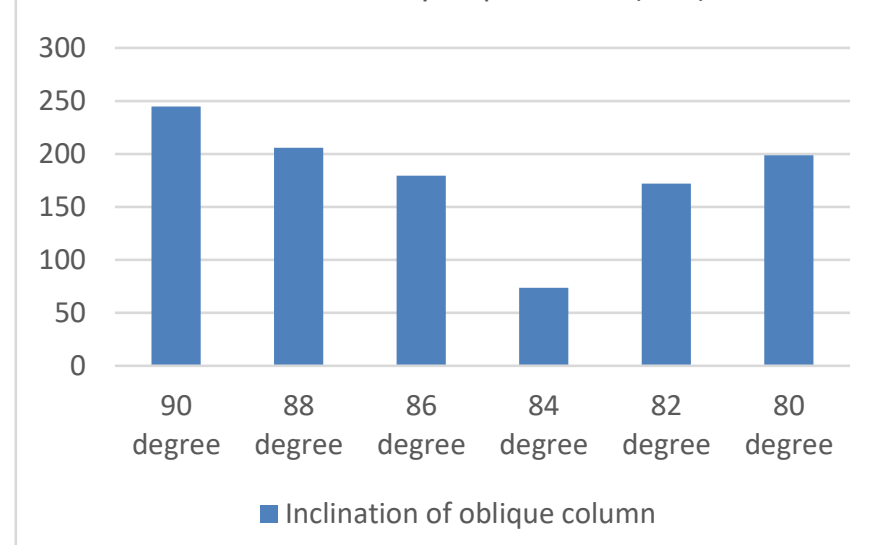

\section{MAXIMUM STOREY DRIFT}

Building with oblique columns of 90degree

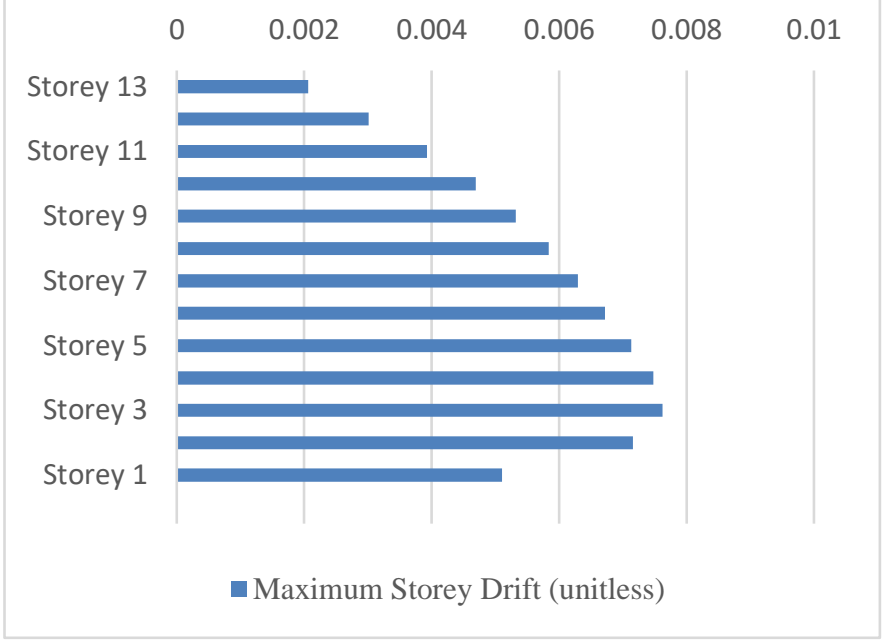

Building with oblique columns of 88 degree

$\begin{array}{lllll}0 & 0.002 & 0.004 & 0.006 & 0.008\end{array}$

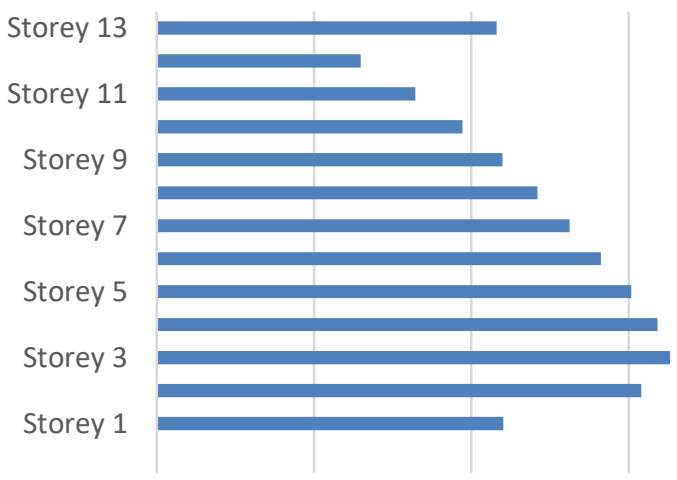

- Maximum Storey Drift (unitless) 
Building with oblique columns of 86 degree

$$
\begin{array}{lllllll}
0 & 0.001 & 0.002 & 0.003 & 0.004 & 0.005 & 0.006
\end{array}
$$

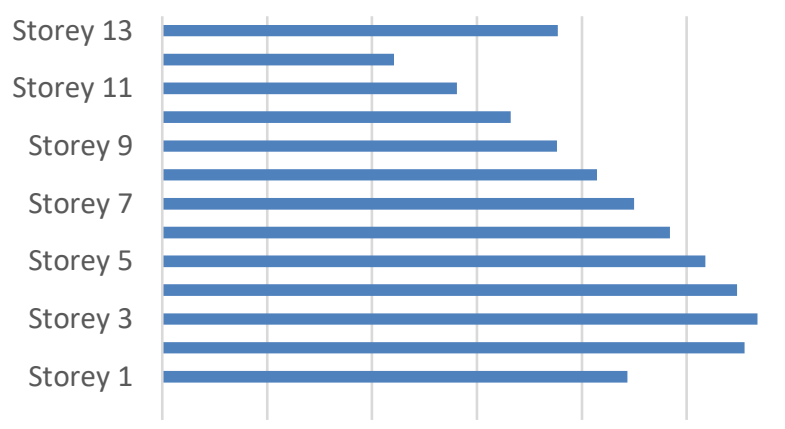

- Maximum Storey Drift (unitless)

Building with oblique columns of 84 degree

$\begin{array}{lllllll}0 & 0.0005 & 0.001 & 0.0015 & 0.002 & 0.0025 & 0.003\end{array}$

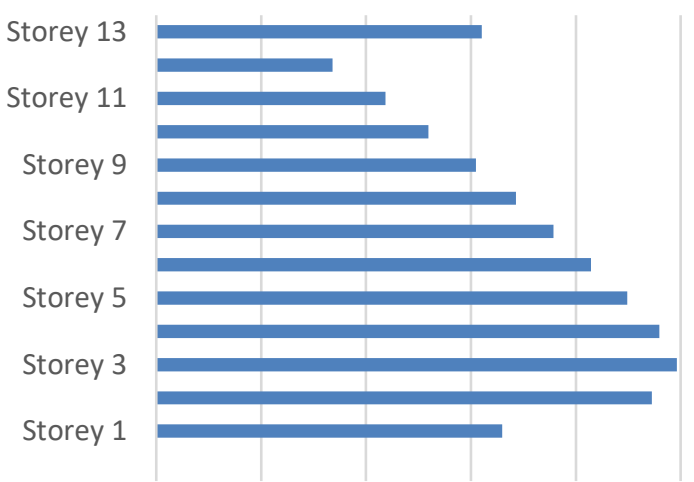

- Maximum Storey Drift (unitless)

Building with oblique columns of 82 degree

$\begin{array}{llllll}0 & 0.002 & 0.004 & 0.006 & 0.008 & 0.01\end{array}$

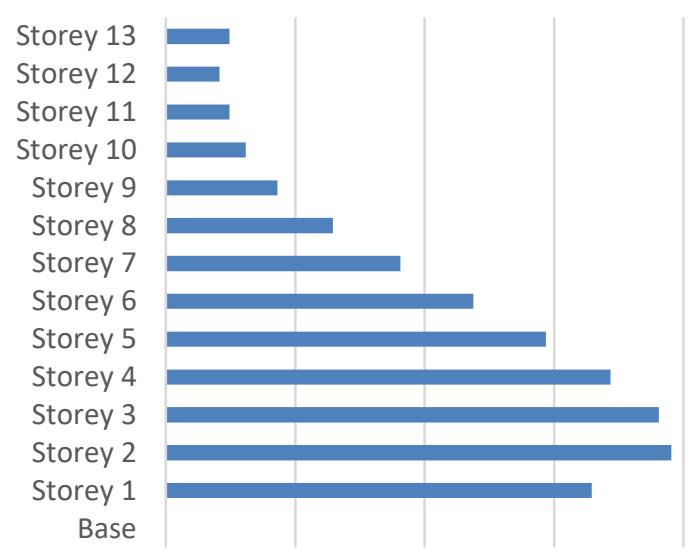

- Maximum Storey Drift (unitless)
Building with oblique columns of 80 degree

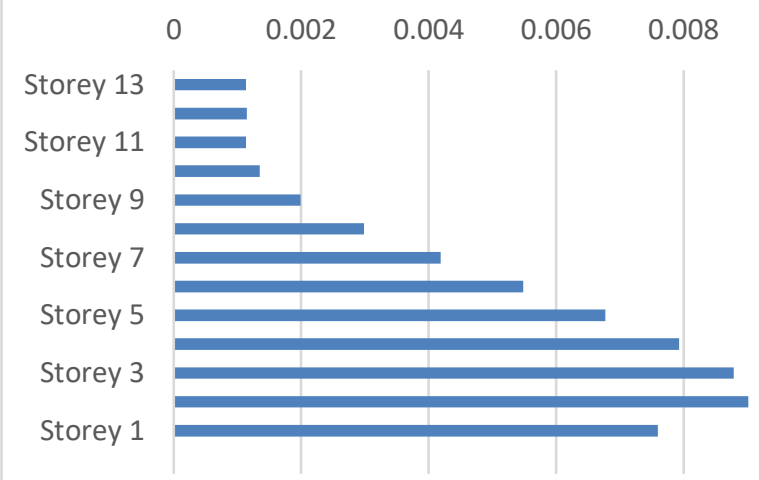

- Maximum Storey Drift (unitless)

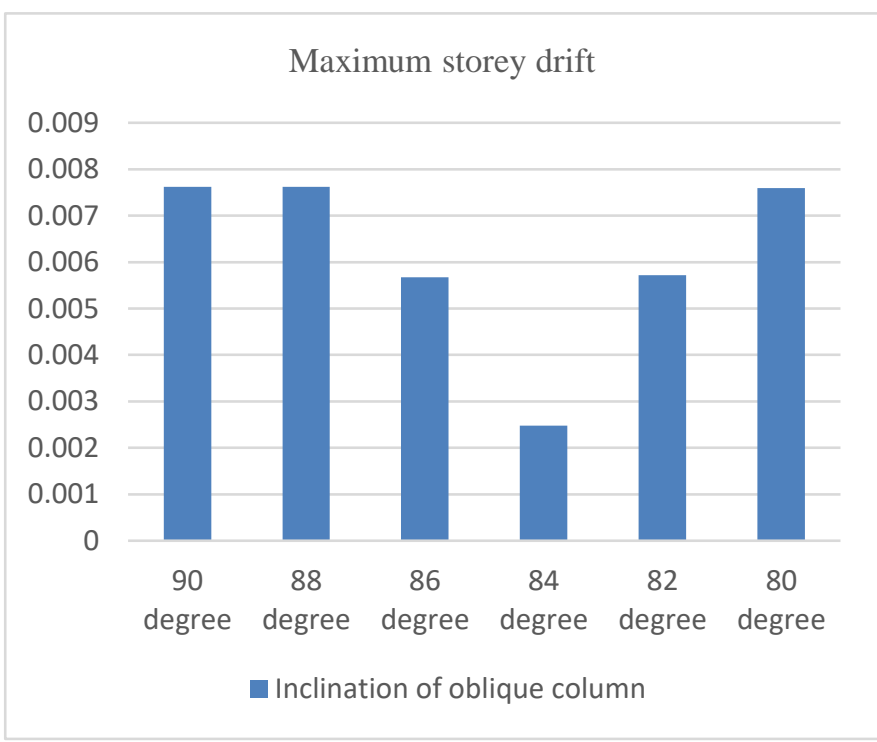

Maximum Storey Drifts of Building with various inclination of Oblique column

\section{ANALYSIS RESULTS}

1- Comparing to multistoried buildings with normal columns, from graph-12 it is evident that multistoried buildings with oblique columns show $69 \%$ lesser maximum story displacement and $28 \%$ lesser story shear uptu certain degree of inclination of oblique columns.

2- Buildings with oblique columns of $88,86,82$ and 80 degrees have $16 \%$ to $19 \%$ lesser top story displacement than conventional column.

3- For the rectangular plan shape of building with oblique columns of 84 degrees is the most efficient angle of inclination as it has $69 \%$ lesser maximum story displacement than conventional column.

4- Building with optimized oblique columns show $67 \%$ lesser story drift than normal columns.

5- Hence the oblique columns are more seismic resistant than conventional columns. 


\section{CONCLUSION}

The structural system with oblique columns is one of the most unique lateral load resisting system for today's tall buildings. The unique compositional characteristics of oblique columns provide lateral stiffness very efficiently and at the same time produce distinguished architectural aesthetics in any existing cityscapes like twisted structures and tilted structures. Today's diverse architectural design directions have produced various non- prismatic building forms such as twisted, tilted, tapered and free forms. This thesis studied lateral performance of structures with oblique columns employed for these complex-shaped tall buildings of various inclinations of oblique columns.

1- As the lateral loads are resisted by structure with Oblique columns, the top storey displacement is very much less in Oblique structure as compared to the simple RC Frame building.

2- As time period is less, lesser is mass of structure and more is the stiffness. The time period is observed less in Structure with Oblique columns. This reflects more stiffness of the structure and lesser mass of structure.

3- Structure provides more resistance in the oblique column building which makes the structural system more effective.

4- From the above all models we will prefer building with oblique columns because it gives better results than buildings with conventional columns.

5- The overall results suggested that Oblique column is excellent seismic control for high-rise symmetric Buildings uptu certain angle of inclination.

\section{FUTURE SCOPE}

1- Effect of oblique columns on inclination greater than 90 degree can be studied further.

2- Effect of oblique columns on different shapes of structures can be studied further.

3- Oblique columns with obliquity in twisted structures can be studied further.

\section{REFERENCES}

[1] Kai Hu, Yimeng Yang, Suifeng Mu, Ge Qu, "Study on High-rise Structure with Oblique Columns by ETABS, SAP2000, MIDAS/GEN and SATWE", Published by Elsevier Ltd. 2011.

[2] Kona Narayana Reddy , Dr.E.Arunakanthi , "A Study on MultiStoreyed Building with Oblique Columns by using ETABS", published by IJIRSET, 2017

[3] Girish kumar G.M and S M Maheswarappa, IJERAT, Volume.4, Issue 8 August -2018.

[4] Megha Kalra, Purnima Bajpai and Dilpreet Singh, "Effect of Wind on Multi Storey Buildings of Different Shapes". Published by Indian Journal of Science and Technology, Vol 9(48), 2016

[5] Azzam KATKHODA , Rana KNAA, "Optimization in the Selection of Structural Systems for the Design of Reinforced Concrete High-rise Buildings in Resisting Seismic Forces". Published by Elsevier Ltd 2012.

[6] Kyoung Sun Moon, "Developments of Structural Systems Toward Mile-High Towers", Published by International Journal of HighRise Buildings, vol-7, 2018.

[7] Muhammad Mostafijur Rahman, Sagar M. Jadhav, Bahram M. Shahrooz, "Seismic performance of reinforce concrete buildings designed according to codes in Bangladesh, India and U.S.". Published by Elsevier Ltd. 2018.

[8] Bureau of Indian Standards: IS-1893, part 1 (2002), Criteria for Earthquake Resistant Design of Structures: Part 1 General provisions and Buildings, New Delhi, India.

[9] Bureau of Indian Standards: IS-875, part 1 (1987), Dead Loads on Buildings and Structures, New Delhi, India.

[10] Bureau of Indian Standards: IS-875, part 3 (1987), Dead Loads on Buildings and Structures, New Delhi, India.

[11] "Seismic Analysis of Structures" by, T. K. Datta (2010)

[12] "Assessment of P-Delta Effect on High Rise Buildings" by Prashant Dhadve1, AlokRao. 